This series is published by the

University of Oslo Department of Economics

P. O.Box 1095 Blindern

N-0317 OSLO Norway

Telephone: +4722855127

Fax: $\quad+4722855035$

Internet: http://www.oekonomi.uio.no/

e-mail: $\quad \underline{\text { econdep } @ \text { econ.uio.no }}$
In co-operation with

\section{The Frisch Centre for Economic Research}

Gaustadalleén 21

N-0371 OSLO Norway

Telephone: $\quad+4722958820$

Fax: $\quad+4722958825$

Internet: http://www.frisch.uio.no/

e-mail: $\quad$ frisch@,frisch.uio.no

List of the last 10 Memoranda:

\begin{tabular}{|ll|l|}
\hline No & 21 & $\begin{array}{l}\text { Jo Thori Lind } \\
\text { Fractionalization and the size of government. 50 pp. }\end{array}$ \\
\hline No 20 & $\begin{array}{l}\text { Michael Hoel, Tor Iversen, Tore Nilssen and Jon Vislie } \\
\text { Genetic testing and repulsion from chance. 20pp. }\end{array}$ \\
\hline No & 19 & $\begin{array}{l}\text { Jon Vislie } \\
\text { Domestic Environmental Policy under Asymmetric Information: The } \\
\text { role of foreign ownership, outside options and market power 34 pp. }\end{array}$ \\
\hline No & 18 & $\begin{array}{l}\text { Karl Ove Moene and Michael Wallerstein } \\
\text { Income Inequality and Welfare spending: } \\
\text { A disaggregated Analysis. 53 pp. }\end{array}$ \\
\hline No 17 & $\begin{array}{l}\text { Siwan Anderson, Jean-Marie Baland and Karl Ove Moene } \\
\text { Sustainability and organizational design in informal groups, with some } \\
\text { evidence from Kenyan Roscas. 49 pp. }\end{array}$ \\
\hline No 16 & $\begin{array}{l}\text { Halvor Mehlum, Karl Ove Moene and Ragnat Torvik } \\
\text { Parasites 19 pp. }\end{array}$ \\
\hline No & 15 & $\begin{array}{l}\text { Michael Wallerstein and Karl Ove Moene } \\
\text { Does the Logic of Collective Action Explain the Logic of Corporatism?. } \\
\text { 42 pp. }\end{array}$ \\
\hline No & 14 & $\begin{array}{l}\text { Sheetal K. Chand } \\
\text { Stabilizing Poverty In The Context Of The IMF's Monetary Model. 31 } \\
\text { pp. }\end{array}$ \\
\hline No 13 & $\begin{array}{l}\text { Knut Røed and Oddbjørn Raaum } \\
\text { The Effect of Programme Participation on the Transition Rate from } \\
\text { Unemployment to Employment. 42 pp. }\end{array}$ \\
\hline No 12 & $\begin{array}{l}\text { Hilde C. Bjørnland } \\
\text { A stable demand for money despite financial crisis: The case of } \\
\text { Venezuela. 19 pp. }\end{array}$ \\
\hline
\end{tabular}

A complete list of this memo-series is available in a PDF® format at: http://www.oekonomi.uio.no/memo/ 
August 4, 2003

\title{
Climate Policy under Technology Spillovers ${ }^{\mathrm{a}}$ \\ Rolf Golombek ${ }^{\mathrm{b}}$ and Michael Hoel ${ }^{\mathrm{c}}$
}

\begin{abstract}
We study climate policy when there are technological spillovers between countries, and there is no instrument that (directly) corrects for these externalities. Without an international climate agreement, the (non-cooperative) equilibrium depends on whether countries use tradable quotas or carbon taxes as their environmental policy instruments. All countries are better off in the tax case than in the quota case. Two types of international climate agreements are then studied: One is a Kyoto type of agreement where each country is assigned a specific number of internationally tradable quotas. In the second type of agreement a common carbon tax is used domestically in all countries. None of the cases satisfy the conditions for the social optimum. Even if the quota price is equal to the Pigovian level, R\&D investments will be lower than what is socially optimal in the Kyoto case. It is also argued that the quota agreement gives higher R\&D expenditures and more abatement than the tax agreement.
\end{abstract}

Keywords: Climate policy, international environmental agreements, R\&D, technology spillovers.

JEL classification: O30; H23; Q20; Q28; Q48

\footnotetext{
a We are indebted to Pertti Haaparanta, Cathrine Hagem and Snorre Kverndokk for comments and suggestions. Earlier versions of this paper have been presented at various seminars and workshops in Stockholm, Helsinki, Tilburg, Heidelberg, and Oslo. We thank the participants for their comments. Research support of the Research Council of Norway under the programme SAMSTEMT is gratefully acknowledged.

${ }^{\mathrm{b}}$ Frisch Centre, Gaustadalleen 21, N-0349 Oslo, Norway (rolf.golombek@frisch.uio.no)

${ }^{\mathrm{c}}$ Department of Economics, University of Oslo, P.O. Box 1095 Blindern, N-0317 Oslo, Norway (m.o.hoel@econ.uio.no)
} 


\section{Introduction}

Most scientists would agree that if dramatic future climate changes are to be avoided, there must be a significant reduction in worldwide greenhouse gas (GHG) emissions compared with the "business as usual" (BAU) development of emissions. If all of these reductions were to take place only through existing technologies, costs of reducing GHG emissions may become very high. Due to increasing abatement costs, technological development will most likely play an important role in curbing growth in emissions. It is therefore important to incorporate factors influencing technological change in climate policy analyses.

During the last decade, several articles have studied interactions between endogenous technological change and environmental policy, see e.g. Jaffe et al. (2002) and Löschel (2002) for overviews. Several of these studies are particularly relevant for issues related to climate policy. However, many of these disregard interactions between countries, and simply consider the world as one unit with a central planner ${ }^{1}$. The present paper focuses explicitly on interactions between countries, and is in this respect related to the studies by e.g. Ploeg and de Zeeuw (1994), Xepapadeas (1995), Katsoulacos (1997), Buonanno et al. (2003), Rosendahl (2002).

In our study there are two types of interactions. Firstly, R\&D efforts in one country, which raise the technology level of the country, are also beneficial for other countries through technology spillovers. This feature of our model is shared by the studies referred to above ${ }^{2}$. Secondly, increased emissions of GHG in one country are harmful also for other countries.

With two types of externalities - positive externalities due to technology spillovers and negative environmental externalities of GHG emissions - standard economic theory suggests that two instruments should be used in order to reach the social optimum. While GHG emissions can be controlled efficiently through e.g. carbon

\footnotetext{
${ }^{1}$ See e.g. Carraro (1998), Fischer (2000), Goulder and Mathai (2000), Goulder and Schneider (1999), Nordhaus (2000), Rasmussen (2001).

${ }^{2}$ Rosendahl (2002) does not include R\&D expenditures in his model. Instead, he assumes that technology levels are endogenized through learning by doing effects (or, more accurately, through "learning by abatement" effects).
} 
taxes or tradable permits, there is virtually no measure that (directly) correct for technology spillovers between countries.

The lack of an instrument reflects that the magnitude of $R \& D$ expenditures in a country is difficult to verify by other countries. If a country is required - through an international agreement - to have more $R \& D$ expenditures than what is individually rational for the country, it will be relatively easy for the country to have less R\&D than required by the agreement, but to report other expenditures as $R \& D$ activities. The purpose of the present paper is therefore to study climate policy when there are technology spillovers between countries, but there is no instrument to correct for these externalities. In particular, we compare the properties of different international climate agreements when the positive externalities from $R \& D$ are not regulated through the climate agreement.

None of the studies referred to above have the same focus as ours. The focus of Ploeg and de Zeeuw (1994) and Xepapadeas (1995) is a comparison of the non-cooperative equilibrium with the first best optimum. However, none of these studies demonstrate that the non-cooperative equilibrium depends on what policy instruments countries use to reduce emissions. This is a topic discussed in Section 3 of our paper.

Buonanno et al. (2003) make a simulation study calculating the costs of the Kyoto agreement under various assumptions about technological development, while Buonanno et al. (2000) analyze the effects of restricting free trade of quotas under the same type of agreement. Similar analyses have been done by Millok (2000) and Kemfert (2001). None of these studies compare a Kyoto type of agreement with an agreement that specifies policies (in stead of emissions) for each country. This is a topic discussed in Section 4 of our paper.

In our analysis, each country is faced by three types of costs; R\&D expenditures, abatement costs, and environmental costs, the latter being determined by the sum of emissions from all countries. Each country seeks to minimize the sum of these costs. While R\&D investments are costly, increased R\&D improves the technology of the country and lowers abatement costs (both absolute and marginal abatement costs at any given level of abatement). Improved technology may also lower BAU emissions 
of the country. A country can also reduce its emissions - and hence its environmental costs - directly through abatement, which is defined as costly activities that reduce emissions using known technologies.

Throughout the paper we assume that in each country $R \& D$ expenditures are controlled directly by the government. This could be interpreted as follows: Due to technology spillovers - both between countries and between domestic firms - the incentives for any particular firm to undertake $R \& D$ expenditures are weak. The government must therefore finance the R\&D activities, even though R\&D (primarily) takes place in private firms. The government thus controls R\&D expenditures through its funding of them.

The rest of the paper is organized as follows. In Section 2 we present the model in more detail and derive the social optimum. In order to keep the analysis as simple as possible, we use a static framework, thus ignoring, for example, the fact that GHG emissions are stock pollutants. Moreover, all types of uncertainties - like the rate of return on $R \& D$ investments - are disregarded. Finally, to keep formulations simple we only consider one type of GHG, namely $\mathrm{CO}_{2}$. None of our results are affected by the latter simplification.

The case of no international agreement is studied in Section 3. Without an agreement, in each country abatement, as well as R\&D expenditures, are determined noncooperatively. Obviously, given the nature of the two inter-country externalities, a non-cooperative equilibrium will have too much emissions and too little R\&D expenditures compared with the social optimum. We also find that the noncooperative equilibrium depends on whether countries use tradable quotas or a carbon tax as their domestic instrument for controlling emissions. However, all countries are better off in the tax case than in the quota case. In Section 3.3 we demonstrate that if the type of policy instrument and the magnitude of the instrument (i.e. the amount of quotas or the rate of the carbon tax) are chosen simultaneously, there are multiple Nash equilibria. If, however, the game runs over two stages, where each country chooses its instrument in the first stage, the unique sub-game perfect equilibrium is for all countries to use a carbon tax to control $\mathrm{CO}_{2}$ emissions. 
In Section 4 we turn to the case of international climate agreements with full participation. Although there are positive externalities from R\&D expenditures, we assume that such expenditures are not regulated through the climate agreement, and are thus determined non-cooperatively (see the discussion above). We consider two types of international agreements. One is a Kyoto type of agreement, i.e. an agreement where each country is assigned a specific number of internationally tradable quotas. Moreover, countries decide themselves how to implement the appropriate emissions domestically. The second type of climate agreement dictates that a common policy should be used domestically in all countries. In our simple model this policy is a carbon tax set at a common level.

Sections 4.1-4.3 give a discussion and comparison of these two types of agreements. Not surprisingly, none of the cases satisfy the conditions for the social optimum. Even if the total number of quotas is set so that the quota price is equal to the Pigovian level (the sum of marginal environmental costs), R\&D investments will be lower than what is socially optimal in the Kyoto case. We also show that for a certain set of conditions, the Kyoto type of agreement gives highest $R \& D$ expenditures and largest abatement.

In Section 5 we examine the case in which there is an incomplete agreement, i.e. some countries have not signed the agreement (the non-cooperating countries). If there is no abatement in the non-cooperating countries, there is virtually no difference between this case and the case of full cooperation.

Next we study the case in which the cooperating countries can purchase CDM ("Clean Development Mechanism") quotas from the non-cooperating countries. The price of CDM quotas is assumed equal to the marginal abatement cost in the noncoopering countries. This gives a supply function for the CDM quotas, with the quota price being higher the more such quotas are purchased by the cooperating countries. Increased R\&D in the cooperating countries will increase the supply of CDM quotas since technology spillovers to the non-signatories lowers their marginal costs of abatement. In order to keep the price of CDM quotas low, the group of cooperating countries acts as a monopsonist towards the non-cooperating countries and purchases less CDM quotas than it would have had the price of CDM quotas been taken as 
given. Abatement in the non-cooperative countries will therefore be less than full cost-effectiveness suggests.

Comparing the first best optimum of the group of cooperating countries with the case of an incomplete Kyoto type of agreement with CDM quotas, as before the Kyoto type is inferior, having too low technology levels. The reasons are similar to the case of full participation in the climate agreement. In fact, in the present case there is even a further source of distortion: A cooperating country takes the price of CDM quotas as given (provided the country is "small"), and therefore neglects the beneficial effect of its $R \& D$ expenditures on the price of CDM quotas (via the positive shift of the supply function of CDM quotas).

Section 6 sums up our main findings and point at some extensions.

\section{The basic model and the social optimum}

According to Rivera-Batiz and Romer (1991) there are two main channels of technological diffusion. First, direct international learning about foreign technological knowledge. Second, technology diffuses internationally through foreign intermediate goods; employing foreign intermediate goods involves the implicit usage of the design knowledge that was created with the $R \& D$ investment of the foreign inventor. Because the latter type of diffusion might be related to international trade and foreign direct investment, it is disregarded in the present paper as we focus solely on innovation and diffusion of green technology.

In order to focus on the relationship between climate policy and technology spillovers, we simplify the modelling of R\&D as much as possible. First, we neglect the dynamic aspects of R\&D. Second, there are no patents, and third all uncertainties are neglected. We assume that the technology level in a country $i, i=1,2,, m$, depends on the amount invested in R\&D in that country, $x_{i}$, and also the investments in $R \& D$ undertaken in all other countries. However, technological diffusion is not 
perfect, only part of the R\&D investments undertaken in other countries $(0<\gamma<1)$ are beneficial for country $i{ }^{3}$ Hence, the technology level of country $i$ is given by:

$$
y_{i}=x_{i}+\gamma \sum_{k \neq i} x_{k}
$$

This way of modelling international knowledge spillovers is very similar to the approach used in the literature referred to above. The assumptions used by Ploeg and de Zeeuw (1994) and Xepapadeas (1995) correspond to the limiting case of $\gamma=1$, while the assumptions used by e.g. Buonanno et al. (2000, 2003) and Rosendahl (2002) correspond to $\gamma<1$.

In the absence of any explicit abatement activities, emissions in each country are assumed to depend only on the technology level of the country. Denoting this business as usual (BAU) emission level in country $i$ by $N_{i}\left(y_{i}\right)$, we assume that $N_{i}^{\prime} \leq 0$ and $N_{i}^{\prime \prime} \geq 0$. Actual emissions are equal to BAU emissions minus abatement, i.e.

$$
E_{i}=N_{i}\left(y_{i}\right)-A_{i}
$$

Abatement costs are assumed to depend both on the level of abatement and the technology level of the country, $C_{i}\left(A_{i}, y_{i}\right)$, where $C_{i A}^{\prime}={ }^{\partial C_{i}} / \partial A_{i}>0, C_{i A A}^{\prime \prime}>0, C_{i y}^{\prime}<0$, $C_{i y y}^{\prime \prime}>0, C_{i A y}^{\prime \prime}<0$ and $C_{i A A}^{\prime \prime} C_{i y y}^{\prime \prime}-\left(C_{i A y}^{\prime \prime}\right)^{2}>0$ (i.e. the $C_{i}$ functions are strictly convex).

Finally, in each country environmental damage depends on the sum of total emissions; $D_{i}\left(\sum_{j} E_{j}\right)$, and we assume that these functions are increasing and convex.

Assuming that there are no restrictions on transfers between countries, the social level of abatement is found from minimizing total costs (aggregated over all countries), including environmental costs, i.e. by minimizing

\footnotetext{
${ }^{3}$ Keller (2002) finds that technology to a substantial degree is local, not global, as the benefits from spillovers are declining with distance. In the present paper we simplify by assuming that for each country, the international diffusion parameter $\gamma$ does not differ between all the other countries. None of our results are affected by this simplification.
} 


$$
\begin{aligned}
& \sum_{i}\left[x_{i}+C_{i}\left(A_{i}, y_{i}\right)+D_{i}\left(\sum_{j} E_{j}\right)\right] \\
& =\sum_{i}\left[x_{i}+C_{i}\left(A_{i}, x_{i}+\gamma \sum_{k \neq i} x_{k}\right)+D_{i}\left(\sum_{j}\left(N_{j}\left(x_{j}+\gamma \sum_{k \neq j} x_{k}\right)-A_{j}\right)\right)\right]
\end{aligned}
$$

The first order conditions for this problem are given by ${ }^{4}$ :

$$
\begin{gathered}
1=\left(-C_{i y}^{\prime}-\gamma \sum_{k \neq i} C_{k y}^{\prime}\right)+\left(-N_{i}^{\prime}-\gamma \sum_{k \neq i} N_{k}^{\prime}\right) \sum_{j} D_{j}^{\prime} \\
C_{i A}^{\prime}=\sum_{j} D_{j}^{\prime}
\end{gathered}
$$

According to (4) at the margin increased costs of R\&D in a country (1) should be balanced against its total benefits. These benefits are of two kinds. First, increased $\mathrm{R} \& \mathrm{D}$ investments in a country reduce abatement costs for the country $\left(-C_{i y}^{\prime}\right)$ and for other countries through technological diffusion $\left(-\gamma \sum_{k \neq i} C_{k y}^{\prime}\right)$. Second, even with unchanged abatement emissions will be lowered in the country undertaking the R\&D investment $\left(-N_{i}^{\prime}\right)$ and also in the other countries through technological diffusion $\left(-\gamma \sum_{k \neq i} N_{k}^{\prime}\right)$. The value of this emission reduction is measured by $\sum_{j} D_{j}^{\prime}$, that is, marginal costs of emissions aggregated over all countries. Moreover, according to (5) marginal costs of abatement (with respect to abatement; $C_{i A}^{\prime}$ ) should equal the marginal benefit following from reduced emissions $\left(\sum_{j} D_{j}^{\prime}\right)$.

\section{No international agreement}

In this section we assume that there is no international agreement. Instead, each country determines investments in $R \& D$ and abatement by balancing costs against benefits following from reduced emissions of $\mathrm{CO}_{2}$. While investments in $\mathrm{R} \& \mathrm{D}$ are controlled by the government and thus determined directly, the government does not control abatement directly. Instead, domestic measures are imposed in order to achieve the desired level of abatement. We assume until Section 3.4 that the countries

\footnotetext{
${ }^{4}$ Throughout the paper, we assume that the non-negativity constraints $x_{i} \geq 0$ and $A_{i} \geq 0$ are not binding, unless the opposite is explicitly stated.
} 
collectively decide on type of domestic instrument for controlling emissions, and that all countries are committed to this choice.

In Section 3.1 we study the case in which each country is committed to use domestic tradable emission quotas to reach its desired abatement level. The second case we study (Section 3.2) is the one in which each country is committed to use a domestic carbon tax. In this case the policy variable is thus not the sum of domestic emissions, but a domestic tax that, along with the level of technology, determines abatement. In both cases we find the Nash equilibrium, assuming that all decisions are taken simultaneously, and that each country minimises its total costs. The Nash equilibria of the two games are compared in Section 3.3. Finally, multiple Nash equilibria are discussed in Section 3.4.

\subsection{Domestic tradable quotas as the chosen policy instrument}

Assume that the government in each country makes a simultaneous decision about the level of the country's R\&D expenditures and the country's total emissions. This total emission level is thereafter distributed to the private agents of the economy through tradable permits. The game considered in this section is thus a game in which country $i$ chooses its emissions and its $\mathrm{R} \& \mathrm{D}$ expenditures to minimize

$$
\left.x_{i}+C_{i}\left(N_{i}\left(y_{i}\right)-E_{i}, x_{i}+\gamma \sum_{k \neq i} x_{k}\right)+D_{i}\left(\sum_{j} E_{j}\right)\right)
$$

taking emission levels and $R \& D$ expenditures in other countries as given. The first order conditions to this minimization problem can be written as

$$
\begin{gathered}
1=-C_{i y}^{\prime}+\left(-N_{i}^{\prime}\right) D_{i}^{\prime} \\
C_{i A}^{\prime}=D_{i}^{\prime}
\end{gathered}
$$

Relations (7) and (8) determine the Nash equilibrium, that is, abatement levels and investments in R\&D in all countries. Comparing this with the social optimum given by (4) and (5), we immediately see that there are three differences. First, in the Nash 
equilibrium each country valuates changes in emissions only through its marginal environmental cost $\left(D_{i}^{\prime}\right)$ and not the total marginal environmental costs $\left(\sum_{j} D_{j}^{\prime}\right)$ as in the social optimum. The second and third difference is that in the Nash equilibrium each country ignores the impact of its $R \& D$ investment on abatement costs in other countries through technological diffusion, both directly $\left(-\gamma \sum_{k \neq i} C_{k y}^{\prime}\right)$ and through making it possible for other countries to achieve their given emission levels through lower abatement due to BAU emissions being lower $\left(-\gamma \sum_{k \neq i} N_{k}^{\prime}\right) C_{k A}^{\prime}$ (The latter expression being equal to $\left(-\gamma \sum_{k \neq i} N_{k}^{\prime}\right) \sum_{j} D_{j}^{\prime}$ in the social optimum).

\subsection{A carbon tax as the chosen policy instrument}

We now assume that the government in each country uses a domestic tax $\tau_{i}$ in order to control domestic abatement. The government in each country makes a simultaneous decision about the level of the country's R\&D expenditures and the country's total emissions. Once all R\&D expenditures and tax rates are determined, private agents in each country will then choose emissions so that marginal costs of abatement are equal to the tax:

$$
C_{i A}^{\prime}\left(A_{i}, y_{i}\right)=\tau_{i}
$$

From (9) we find that abatement in a country depends on the tax imposed in the country and the technology level of the country:

$$
A_{i}=A_{i}\left(\tau_{i}, y_{i}\right)
$$

where our assumptions of the abatement cost function imply that $A_{i \tau}^{\prime}>0, A_{i y}^{\prime}>0$.

The important difference between the present case and the quota case is that when a country chooses its R\&D expenditures, emissions in other countries are not given in 
the present case. On the contrary, in the present case the choice of $x_{i}$ affects $y_{j}$ and thus $E_{j}=N_{j}\left(y_{j}\right)-A_{j}\left(\tau_{j}, y_{j}\right)$ for all $j$.

When governments control abatement through a domestic tax, the government chooses the tax and R\&D expenditures to minimize

$$
\begin{aligned}
x_{i}+ & C_{i}\left(A_{i}\left(\tau_{i}, x_{i}+\gamma \sum_{k \neq i} x_{k}\right), x_{i}+\gamma \sum_{k \neq i} x_{k}\right)+ \\
& D_{i}\left(\sum_{j}\left(N_{j}\left(x_{j}+\gamma \sum_{k \neq j} x_{k}\right)-A_{j}\left(\tau_{j}, x_{i}+\gamma \sum_{k \neq j} x_{k}\right)\right)\right)
\end{aligned}
$$

The first order conditions are now given by (8) and

$$
1+C_{i A}^{\prime} A_{i y}^{\prime}=-C_{i y}^{\prime}-D_{i}^{\prime}\left(N_{i}^{\prime}+\gamma \sum_{k \neq i} N_{k}^{\prime}\right)+D_{i}^{\prime}\left(A_{i y}^{\prime}+\gamma \sum_{k \neq i} A_{k y}^{\prime}\right)
$$

Using (8), this equation may be rewritten as

$$
1=-C_{i y}^{\prime}+\left(-N_{i}^{\prime}-\gamma \sum_{k \neq i} N_{k}^{\prime}+\gamma \sum_{k \neq i} A_{k y}^{\prime}\right) D_{i}^{\prime}
$$

Comparing this with the social optimum given by (4) and (5), we immediately see that there are three differences. First, just like the case where countries use quotas as their instruments, in the Nash equilibrium, each country valuates changes in emissions only through its own marginal environmental cost $\left(D_{i}^{\prime}\right)$ and not the total marginal environmental costs $\left(\sum_{j} D_{j}^{\prime}\right)$ as in the social optimum. The second difference is that in the Nash equilibrium, each country ignores the direct impact of its R\&D investment on abatement costs in other countries through technological diffusion $\left(-\gamma \sum_{k \neq i} C_{k y}^{\prime}\right)$.

Like in the social optimum increased $R \& D$ investment in a country will lower BAU emissions in all countries. On the other hand, in the Nash equilibrium each country takes into account that its own R\&D expenditures will (in addition) have a positive impact on abatement in other countries $\left(\gamma \sum_{k \neq i} A_{k y}^{\prime}\right)$; this term does not appear in the first order conditions for the social optimum. 


\subsection{A comparison of the two non-cooperative equilibria}

We wish to compare the two types of non-cooperative equilibria, which we denote the quota equilibrium (section 3.1) and the tax equilibrium (section 3.2). Condition (8) is valid in both equilibria. However, the conditions for optimal R\&D differ: Comparing (13) with (7), we see that (13) has an additional positive term $\left(\gamma\left(-\sum_{k \neq i} N_{k}^{\prime}+\sum_{k \neq i} A_{k y}^{\prime}\right) D_{i}^{\prime}\right)$ compared with (7). The interpretation of this term is that when tax rates in all countries are given, increased $R \& D$ investment in a country will reduce emission levels in other countries because of technological diffusion. This additional term implies that the marginal benefits of R\&D investments for each country increase, and hence the incentives for R\&D expenditures increase. Since BAU emissions and abatement costs are lower the higher are R\&D expenditures, we therefore expect emissions to be lower under the tax equilibrium than under the quota equilibrium. In the Appendix we prove that this intuition turns out to hold, i.e., we have the following result:

Proposition 1: Total emissions are lower in the non-cooperative tax equilibrium than in the non-cooperative quota equilibrium.

Although total emissions are lower in the non-cooperative tax equilibrium than in the non-cooperative quota equilibrium, this does not necessarily imply that R\&D expenditures in all countries are higher in the tax equilibrium than in the quota equilibrium. In the Appendix we prove the following slightly weaker result:

Proposition 2: For countries that have linear environmental damage functions (i.e. $\left.D_{i}^{\prime \prime}=0\right)$, technology levels and abatement levels are higher in the non-cooperative tax equilibrium than in the non-cooperative quota equilibrium. Hence for these countries, emissions are lower in the non-cooperative tax equilibrium than in the noncooperative quota equilibrium. 
To see why we need the assumption of linear environmental damage functions in Proposition 2, assume all countries except country 1 have linear environmental damage functions. For country 1 , assume that $D_{1}^{\prime}$ is zero when the sum of emissions is below some threshold $E^{*}$, and positive when the sum of emissions exceeds $E^{*}$. From Proposition 2 we know that emissions in all other countries are lower in the tax equilibrium than in the quota equilibrium. Assume therefore that the sum of emissions from countries $2, . ., m$ exceeds $E^{*}$ in the quota equilibrium, but are lower than $E^{*}$ in the tax equilibrium. Country 1 will therefore have positive abatement in the quota equilibrium, but zero abatement in the tax equilibrium. ${ }^{5}$ For this case it is thus not true that all countries have higher abatement levels in the tax equilibrium than in the quota equilibrium.

With linear environmental damage functions, although technology levels are highest in all countries in the tax equilibrium we cannot conclude that $R \& D$ expenditures are highest in the tax equilibrium. This can be seen by considering the 2-country case. For this case it follows from (1) that $x_{1}=\left(y_{1}-\gamma y_{2}\right) /\left(1-\gamma^{2}\right)$ and $x_{2}=\left(y_{2}-\gamma y_{1}\right) /\left(1-\gamma^{2}\right)$. Even if both countries have linear environmental damage cost functions, we cannot rule out that as we move from the quota to the tax equilibrium, $y_{2}$ increases much more than $y_{1}$ : The change in $y_{i}$ depends on the second order derivative $C_{i A A}^{\prime \prime}$ (see (A4) in the Appendix for details), and these second order derivatives may differ strongly between countries. If $y_{2}$ increases much more than $y_{1}$ as we move from the quota to the tax equilibrium, $R \& D$ expenditures in county 1 will be lower in the tax equilibrium than in the quota equilibrium.

According to Proposition 2, technology levels are highest in all countries in the tax equilibrium provided that all $D_{i}^{\prime \prime}=0$. Hence, if $D_{i}^{\prime \prime}=0$ and all countries are identical, the common technology level is highest in the tax equilibrium, and thus R\&D expenditures are highest in the tax equilibrium. It turns out that this result holds also for $D_{i}^{\prime \prime}>0$ if all countries are identical:

\footnotetext{
${ }^{5}$ Country 1 will also have $x_{1}=0$ in the tax equilibrium, and in this case we may have a corner solution so that the " $="$ in (13) is replaced by " $>$ " for $i=1$.
} 
Proposition 3: If countries are identical, $R \& D$ expenditures are higher in the noncooperative tax equilibrium than in the non-cooperative quota equilibrium.

Proof: We know from Proposition 1 that with $E^{T}<E^{Q}$, implying $D^{\prime}\left(E^{T}\right) \leq D^{\prime}\left(E^{Q}\right)$ (omitting subscripts since countries are identical). From (8) this implies $C_{A}^{\prime}\left(A^{T}, y^{T}\right) \leq C_{A}^{\prime}\left(A^{Q}, y^{Q}\right)$. Assume $y^{T} \leq y^{Q}$. From the properties of the abatement cost functions this implies $A^{T} \leq A^{Q}$. Taken together, the two last inequalities imply $E^{T} \geq E^{Q}$, which contradicts Proposition 1 . We therefore must have $y^{T}>y^{Q}$. Since $\mathrm{y}=\mathrm{x}+\gamma(\mathrm{m}-1) \mathrm{x}$ when there are $\mathrm{m}$ equal countries, it follows that $x^{T}>x^{Q} \cdot Q E D$

From the propositions above, it is clear that the following must be true when countries are identical:

Proposition 4: If countries are identical, all countries are better off in the noncooperative tax equilibrium than in the non-cooperative quota equilibrium.

Proof: This follows directly from the fact that with identical countries each country has more $R \& D$ investment and lower emissions in the tax equilibrium than in the quota equilibrium. As for the country's own policy, in both cases R\&D expenditure and abatement are chosen (directly or indirectly through an appropriate carbon tax) in order to maximize the country's own welfare. Any particular country is cet. par. better off the higher are the levels of R\&D investments and abatement in other countries. A country is thus better off when other countries use taxes than when other countries use quotas. ${ }^{6} Q E D$

\footnotetext{
${ }^{6}$ A country could (hypothetically) choose R\&D investment and abatement level from the quota equilibrium even if other countries use taxes. It would then be better off than if other countries had used quotas (and thus had higher emissions and less R\&D). Of course, the country is even better off when it chooses R\&D and abatement according to the tax equilibrium (given that all other countries use taxes).
} 


\subsection{Endogenous type of policy}

In Section 3.1 we studied the corner case in which all countries use domestic tradable quotas in order to reach the equilibrium emission level. Likewise, in Section 3.2 we examined the corner case in which all countries use a carbon tax as their domestic instrument. There are, however, more equilibria. First, note that given the choice of domestic policy instrument in the other countries, for the last country there is a particular abatement level and level of R\&D investments that maximize the country's welfare. These levels will of course depend on what other countries do, and in particular on how many countries use quotas and how many countries use taxes. But whatever the optimal level of R\&D investments and abatement are in a country, it makes no difference to the country's welfare whether the appropriate abatement level is achieved through the use of quotas or through an appropriate carbon tax. Hence, the two Nash equilibria discussed above are only two of many possible Nash equilibria.

The discussion above demonstrates the following proposition:

Proposition 5: If the choice of policy instrument is made simultaneously with the magnitude of the instrument (i.e. amount of quotas or rate of the carbon taxes), there are multiple Nash equilibria.

Suppose, however, that countries (simultaneously) choose type of instrument (quota or tax) in the first stage of a 2-stage game. In the second stage, the level of the instrument, as well as R\&D expenditures, are (simultaneously) chosen. If countries are identical, it follows from the discussion in the end of the previous section that the more countries that have chosen tax in stage 1, the higher are R\&D expenditures and the lower are emissions in stage 2 . If country $i$ chooses tax in stage 1 , it induces higher R\&D expenditures and lower emissions in the other countries than if it had chosen quota in stage 1 . Moreover, in stage 2 it does not matter for a country whether it uses quota or tax as a particular abatement can be reached anyway. All countries are aware of these facts in stage 1 , and hence all countries choose tax in stage 1. Hence, we have the following proposition: 
Proposition 6: Assume that all countries are identical. If the choice of policy instrument in all countries is made before the magnitude of the instrument (i.e. amount of quotas or rate of the carbon taxes), there is a unique sub-game perfect equilibrium of the 2-stage game, where all countries use carbon taxes to control $\mathrm{CO}_{2}$ emissions.

Notice that the assumption of identical countries in the above Proposition was needed only to guarantee that each country has more R\&D investment and lower emissions the larger is the number of other countries choosing a tax as their policy instrument. This will hold if countries are identical, but it will obviously also hold under much weaker assumptions. Proposition 6 can thus be generalized to a broader set of cases than the case of identical countries.

\section{International agreements}

We consider two types of complete international climate agreements. The first type of agreement is a Kyoto type. This agreement specifies the initial distribution of emission quotas between countries, but allows countries to buy or sell quotas from/to other countries. The agreement imposes no restrictions on how a country sets its domestic policy, as long as its emissions does not exceed its quotas (i.e. initial endowment adjusted for quotas purchased or sold).

The second type of agreement does not set any direct limits on the emissions of the countries. Instead, the agreement specifies policy instruments that the countries must implement domestically. Below, we study the case where there is a common domestic carbon tax that all countries must implement.

In the simple case where $R \& D$ investments for a moment are ignored, both types of agreements will in principle give cost-effectiveness, as marginal abatement costs will be equalized across countries in both cases. ${ }^{7}$ Moreover, with a suitable amount of total

\footnotetext{
7 There are obviously several qualifications. In particular, for the Kyoto type agreement we must assume that no country has market power (see e.g. Westskog, 1996) and that domestic policies are efficient in the sense that the costs to a country of emitting $\mathrm{CO}_{2}$ (equal to the international quota price) are passed on to private agents. With a harmonized carbon tax, we must assume that domestic policy is not designed so that the effect of the tax is undermined, see e.g. Hoel (1992a,b; 1993) for a further discussion.
} 
quotas or a suitable level of the common carbon tax, the condition (5) for efficient abatement can be met.

\subsection{Internationally tradable emission quotas}

Assume that country $i$ is given initial emission quotas equal to $\bar{E}_{i}$. Moreover, assume that a competitive international market for quotas is established, with an equilibrium price $\mathrm{p}$ for quotas. Obviously, this price will be higher the smaller is the sum of quotas $\sum_{i} \bar{E}_{i}=\bar{E}$. Assume that all countries are small, in the sense that they consider the quota price as independent of their own decisions. We shall discuss this further in the end of this section. For a given quota endowment $\bar{E}_{i}$ and a given quota $p$, country $i$ minimizes

$$
x_{i}+C_{i}\left(A_{i}, y_{i}\right)+p\left[N_{i}\left(y_{i}\right)-A_{i}-\bar{E}_{i}\right]
$$

subject to (1) and taking $R \& D$ expenditures in other countries as given (that is, $R \& D$ expenditures are determined in a non-cooperative manner). Notice that the environmental cost function $D_{i}$ does not appear here, since the sum of emissions are given.

The first order conditions for this minimization problem are

$$
1=-C_{i y}^{\prime}+\left(-N_{i}^{\prime}\right) p
$$

and

$$
C_{i A}^{\prime}=p
$$

The equilibrium price $\mathrm{p}$ will of course depend on the sum of quotas $\bar{E}$. The lower $\bar{E}$ is, the higher will be the quota price. Moreover, in the Appendix we show the following 
Proposition 7: The higher the quota price p, the higher is abatement and the higher is the technology level in all countries.

If the sum of quotas is set so that the quota price is equal to the Pigovian level, i.e. equal to the sum of marginal environmental costs $\sum_{j} D_{j}^{\prime}$, it is clear that equation (5) from the social optimum will be satisfied. However, the conditions for R\&D expenditures differ: Comparing (15) with (4), we see that (4) has an additional positive term $-\gamma\left(\sum_{k \neq i} C_{k y}^{\prime}+p \sum_{k \neq i} N_{k}^{\prime}\right)$ compared with (15). In other words, the positive spillover effects to the countries are ignored under the Kyoto type of climate agreement. In the Appendix we show that this has the following implication:

Proposition 8: Denote the emission level in country $i$ in the social optimum by $E_{i}^{S O}$. If $p=\sum_{j} D_{j}^{\prime}\left(E_{j}^{S O}\right)$, abatement levels and technology levels will be lower in all countries in the Kyoto type agreement than in the social optimum.

Although a total emission level implying $p=\sum_{j} D_{j}^{\prime}$ may seem as a natural choice, it is in fact better to have a lower sum of emissions. To see this, start with an emission level implying $p=\sum_{j} D_{j}^{\prime}$, and then reduce the sum of emissions. This will give an increase in the quota price $p$. From Proposition 7 we know that the increase in $p$ will imply increased abatement and technology levels. Small changes in abatement levels have a second order effect on total social costs, since (5) holds initially. However, when the initial equilibrium is given by (15), it is shown in the Appendix (by differentiating (3)) that social costs are reduced by small changes in $R \& D$ expenditures that increase all technology levels. We thus have the following result:

Proposition 9: Under a Kyoto type of agreement, the optimal amount of quotas is such that the equilibrium quota price is higher than the Pigovian level $p=\sum_{j} D_{j}^{\prime}$. 
From the discussion above it follows that under a Kyoto type of agreement, the quota price should be "high", that is, the amount of quotas should be "low", in order to adjust for insufficient incentives for the signatories to take technology spillovers into account.

We have so far assumed that all countries consider the quota price as given. For a country that is so large that it takes into consideration that its decisions influence this price we get additional terms in (15) and (16). These are $-\left[N_{i}\left(y_{i}\right)-A_{i}-\bar{E}_{i}\right]\left(d p / d x_{i}\right)$ and $-\left[N_{i}\left(y_{i}\right)-A_{i}-\bar{E}_{i}\right]\left(d p / d A_{i}\right)$, respectively. The size of the terms $d p / d x_{i}$ and $d p / d A_{i}$ will depend on the market structure. The size of the terms $\left[N_{i}\left(y_{i}\right)-A_{i}-\bar{E}_{i}\right]$ will depend on how many quotas large countries buy or sell. In particular, these terms will be zero if the initial quota allocation implies that the large countries decide to neither buy nor sell quotas. Notice that this will be the outcome if all countries are identical and the quotas are distributed equally to all countries.

\subsection{A harmonized domestic carbon tax}

Assume now that the climate agreement does not specify emission levels for the participating countries, but instead requires all countries to introduce a common domestic carbon tax $\tau$. Moreover, in each country the carbon tax revenue of the government is redistributed domestically. For country $i$, the abatement level is now determined by (10), with $\tau_{i}$ replaced by $\tau$.

As in Section 3, there is an important difference between the two types of agreements. With tradable emission quotas (the previous case) emissions in other countries are taken as given. On the other hand, in the present case of a harmonized domestic carbon tax, emissions in other countries are affected by the choice of the country's R\&D expenditures (through the technology levels of the other countries). 
With a harmonized domestic carbon tax country i minimizes

$$
x_{i}+C_{i}\left(A_{i}\left(\tau, y_{i}\right), y_{i}\right)+D_{i}\left(\sum_{j}\left[N_{j}\left(y_{j}\right)-A_{j}\left(\tau, y_{j}\right)\right]\right)
$$

subject to (1). The optimal choice of R\&D expenditures is given by the first order condition (12), which together with (9) may be rewritten as

$$
1=-C_{i y}^{\prime}+\left(-N_{i}^{\prime}-\gamma \sum_{k \neq i} N_{k}^{\prime}+\gamma \sum_{k \neq i} A_{k y}^{\prime}\right) D_{i}^{\prime}-\left(\tau-D_{i}^{\prime}\right) A_{i y}^{\prime}
$$

The two first terms on the r.h.s. of (18) have a straightforward interpretation, see the discussion after (13). Without any agreement the last term would cancel out: the domestic tax rate $\tau_{i}$, which then equals marginal cost of abatement $C_{i A}^{\prime}$, would be equal to marginal benefit of abatement $D_{i}^{\prime}$, see (8). However, with an agreement (the present case) the common tax rate $\tau$ will in general differ from (be higher than) the tax rate the country would have chosen without any agreement, that is, the last term in (18) is negative. The interpretation is that the larger are $R \& D$ expenditures, the larger is abatement, i.e. the more is abatement distorted away from the country's ideal choice (given by (8)). This negative consequence of more R\&D expenditure must be subtracted from the positive effects given by the first two terms.

If the common carbon tax is set at the Pigovian level, i.e. equal to the sum of marginal environmental costs $\sum_{j} D_{j}^{\prime}$, it is clear from (9) that equation (5) from the social optimum will be satisfied. However, also in the present case the R\&D expenditures will generally differ from the socially optimal level, but it is now not obvious whether there will be too little $R \& D$ compared with the social optimum (as in the case considered in the previous section), or too much R\&D. To see this compare (4) and (18): When $\tau=\sum_{j} D_{j}^{\prime}$, there are three differences between (4) and (18): 
- The term $\left(-N_{i}^{\prime}-\gamma \sum_{k \neq i} N_{k}^{\prime}\right)$ is in (4) multiplied by $\sum_{j} D_{j}^{\prime}$, while in (18) it is multiplied by only $D_{i}^{\prime}$. This tends to make the r.h.s. of (18) smaller than the r.h.s. of (4).

- The term $-\gamma \sum_{k \neq i} C_{k y}^{\prime}$ in (4) is replaced by $\gamma\left(\sum_{k \neq i} A_{k y}^{\prime}\right) D_{i}^{\prime}$. It is not clear which of these terms is largest.

- In (18) there is a negative term $-\left(\tau-D_{i}^{\prime}\right) A_{i y}^{\prime}$ that dose not appear in (4). This tends to make the r.h.s. of (18) smaller than the r.h.s. of (4).

From the reasoning above it is clear that we cannot be sure whether (4) or (18) has the largest r.h.s. (for given values of abatement and technology levels). If they are identical for all countries at the values of abatement and technology levels in the social optimum, it is optimal for the carbon tax to be equal to the Pigovian level $\tau=\sum_{j} D_{j}^{\prime}$. If the r.h.s. of (4) and (18) differ for some or all countries, as they generally will, this will usually no longer be true. We can summarize this discussion in the following Proposition:

Proposition 10: Under an agreement of a common carbon tax, the optimal carbon tax will generally differ from the Pigovian level $\tau=\sum_{j} D_{j}^{\prime}$. Whether the optimal tax is lower than or higher than the Pigovian level will depend on properties of the functions describing the economy.

\subsection{A comparison of the two types of agreements}

In this section we compare the two types of international agreements, which also may be labelled "quota" and "tax" types of agreements. We have not been able to make a general comparison. Instead we have considered the case where all countries are identical, and where BAU emission functions and environmental damage functions are linear in their arguments over the relevant ranges. We have used the notation $D_{i}^{\prime}=\delta(>0)$ and $N_{i}^{\prime}=\eta(<0)$, and the comparison between the two cases is done for the same price of carbon, i.e. $p=\tau$. 
With the notation above we can rewrite (15) and (18) as

$$
1=-C_{y}^{\prime}(A, y)-\eta p+K
$$

where $K=0$ under the quota agreement and

$$
K=-\left(A_{y}^{\prime}-\eta\right)[(p-\delta m)+(m-1)(1-\gamma) \delta]
$$

under the tax agreement. In the Appendix we show the following:

Remark 1: Assume that countries are identical and that BAU emission functions and environmental damage functions are linear. If $K$ (given by (20)) is negative (positive) the quota agreement gives higher (lower) $R \& D$ expenditures and more (less) abatement than the tax agreement.

By assumption, $A_{y}^{\prime}-\eta>0$. The square brackets in (20) consist of two terms. The second term is positive. The first term is non-negative if $p \geq \delta m$. Notice that $p=\delta m$ corresponds to the Pigovian case in which the marginal abatement cost is set equal to the sum of the marginal environmental costs. From (20) and Remark 1 we thus have the following result:

Proposition 11: Assume that countries are identical and that BAU emission functions and environmental damage functions are linear. If the price of carbon is at least equal to the Pigovian level, then the quota agreement gives higher $R \& D$ expenditures and more abatement (and thus lower emissions) than the tax agreement.

If the price of carbon is sufficiently lower than the Pigovian level, the result above will be reversed. This confirms our analysis in Section 3, where we showed that without international cooperation, quotas would give lower R\&D expenditures and higher emissions than taxes (for identical countries). Formally, this follows from (20) with $p=\delta$, which corresponds to the case of no agreement. With $p=\delta$, we get 
$K=\left(A_{y}^{\prime}-\eta\right)(m-1) \gamma \delta$, which is positive if there are R\&D spillovers $(\delta>0)$. If there are no such spillovers, of course it then makes no difference whether countries use quotas or taxes in their domestic policies when there is no international agreement.

\section{Incomplete agreements}

The Kyoto agreement will only cover some of the countries in the world. This is likely to be the case for any international agreement: There may always be some countries not being willing to sign the agreement. In this chapter we therefore assume that there is an aggregate of such countries, which we denote by country 0 , in addition to the $\mathrm{N}$ (signatory) countries of our model. The purpose of this chapter is to see how the existence of such an outside country (in reality a group of countries) affects the optimal choice of policies in the cooperating countries.

\subsection{No explicit abatement in the non-cooperating country}

Assume first that there is no active abatement effort in the non-cooperating countries, which may reflect that these countries do not regard the climate problem to be of any significance to it. This could also be the reason why the countries are not interested in joining an international agreement that aims at reducing $\mathrm{CO}_{2}$ emissions.

Even if there is no abatement effort in the non-cooperating countries, the BAU emission level $N_{0}$ could depend on R\&D expenditures in the cooperating countries. Formally, assume that $N_{0}$ is given by the function $N_{0}\left(y_{0}\right)$ that has the same properties as the other $N_{i}$ functions, where

$$
y_{0}=\gamma \sum_{k=1}^{k=N} x_{k}
$$

We have thus implicitly assumed that there are no R\&D expenditures (of the kind relevant for $\mathrm{CO}_{2}$ emissions) in the non-cooperating countries. This is a reasonable description of countries that are not concerned about the environmental effect of $\mathrm{CO}_{2}$ emissions. 
For the cooperating countries, total social costs are given by (3) as before, the only difference being that there is an additional term - $N_{0}\left(y_{0}\right)$ - in the environmental damage functions. The social optimum is as before given by (4) and (5), but with the summation operator in the second term of (4) starting at 0 instead of 1.

Next, consider an international agreement of the quota type, i.e. the type discussed in Section 4.1. Since total emissions are no longer given (incomplete agreement), we must include environmental costs in the expression for total costs of country $i$. Instead of (14) we therefore now have

$$
x_{i}+C_{i}\left(A_{i}, y_{i}\right)+p\left[N_{i}\left(y_{i}\right)-A_{i}-\bar{E}_{i}\right]+D_{i}\left(N_{0}\left(y_{0}\right)+\sum_{j=1}^{j=N} \bar{E}_{j}\right)
$$

where $\mathrm{y}_{0}$ is given by (21). The first order conditions for the minimization of this expression give us (16) as before, and instead of (15) we get

$$
1=-C_{i y}^{\prime}+\left(-N_{i}^{\prime}\right) p+\left(-N_{0}^{\prime}\right) D_{i}^{\prime}
$$

The additional positive term $-N_{0}^{\prime} D_{i}^{\prime}$ on the r.h.s. of (23) implies that there are higher R\&D expenditures in the present case than in the case without non-cooperating countries. However the underinvestment in $R \& D$ is no less than before, as the existence of non-cooperating countries also augments the r.h.s. of (4) by a similar term. In fact, while $-N_{0}^{\prime}$ is multiplied by the sum of marginal environmental costs for all countries in the social optimum, $-N_{0}^{\prime}$ is multiplied only by the marginal environmental costs for country $i$ in (23). Hence, the additional term is largest in the social optimum.

Turning to the tax type of agreement discussed in Section 4.2, the only change in the minimization problem of a country is that the summation operator in (17) starts at 0 instead of 1 , and $A_{0}=0$. The first order condition for this problem is given by (18) as before, but with the first summation operator starting at 0 instead of 1 . 
It is thus clear that for both types of agreement, the only change due to noncooperating countries is the addition of the term $-N_{0}^{\prime} D_{i}^{\prime}$ on the r.h.s. of the equations describing the optimal amount of $R \& D$ expenditure. The comparison between the two types of agreements, given in Section 4.3, thus remains valid also in the present case.

\subsection{A quota agreement with a CDM}

Consider the case in which the cooperating countries can induce the non-cooperating countries to abate its emissions. Decreased emissions in the non-cooperating countries require transfer of money from the cooperating countries to the non-cooperating countries, that is, the signatories buy CDM ("Clean Development Mechanism") quotas from the non-cooperating countries. We assume that the price of CDM quotas $(q)$ is equal to the marginal abatement cost in the non-cooperating country, that is,

$$
q=C_{0 A}^{\prime}\left(A_{0}, y_{0}\right)
$$

where $C_{0 A}^{\prime}\left(A_{0}, y_{0}\right)$ can be interpreted as a supply function of CDM quotas. Hence, increased purchase of CDM quotas will increase the quota price $\left(C_{0 A A}^{\prime \prime}>0\right)$. On the other hand, increased R\&D expenditures among the signatories, which through technology spillovers raise the technology level also in the non-cooperating country, lower the quotas price $\left(C_{0 A y}^{\prime \prime}<0\right)$.

The sum of costs in the cooperating countries is now given by

$$
q A_{0}+\sum_{i=1}^{i=N}\left[x_{i}+C_{i}\left(A_{i}, y_{i}\right)+D_{i}\left(\sum_{j=0}^{j=N} N_{j}\left(y_{j}\right)-A_{j}\right)\right]
$$

where $q A_{0}$ is the payment for abatement in the non-cooperating countries, that is, for the purchase of $A_{0} \mathrm{CDM}$ quotas.

Consider the first best optimum for the group of cooperating countries when the price for $\mathrm{CDM}$ quotas is equal to the marginal abatement cost in the non-cooperating 
countries. Formally, this optimum is found by minimizing (25) subject to the constraints (1), (21) and (24). The first order conditions are

$$
\begin{gathered}
1=\left(-C_{i y}^{\prime}-\gamma \sum_{k \neq i ; k=1}^{k=N} C_{k y}^{\prime}\right)+\left(-N_{i}^{\prime}-\gamma \sum_{k \neq i ; k=0}^{k=N} N_{k}^{\prime}\right) \sum_{j=1}^{j=N} D_{j}^{\prime}-\gamma C_{0 A y}^{\prime \prime} A_{0} \\
C_{i A}^{\prime}=\sum_{j=1}^{j=N} D_{j}^{\prime} \quad i=1, \ldots ., N \\
C_{0 A}^{\prime}+A_{0} C_{0 A A}^{\prime \prime}=\sum_{j=1}^{j=N} D_{j}^{\prime}
\end{gathered}
$$

Except for the differences with respect to which countries the summation operator includes, (26) and (27) are almost identical to (4) and (5). The only difference is the term $-\gamma C_{0 A y}^{\prime \prime} A_{0}$ in (26), which is positive, representing reduced payment to the noncooperating countries: increased $\mathrm{R} \& \mathrm{D}$ expenditures in the cooperating countries lower marginal abatement costs in the non-cooperating countries through technological diffusion, and hence the price $q$ of CDM quotas is reduced.

Equation (28) suggests the optimal amount of purchased CDM quotas for the group of cooperating countries. Since $A_{0} C_{0 A A}^{\prime \prime}>0$, it follows from (27) and (28) that marginal abatement costs should be lower in the non-cooperating countries than in the cooperating countries. The reason is that it is optimal for the group of cooperating countries to act as a monopsonist towards the non-cooperating countries. By purchasing less abatement in the non-cooperating countries than full costeffectiveness would suggest, the price of CDM quotas (equal to marginal costs of abatement in the non-cooperating countries) is kept down.

We now turn to the case of a Kyoto type of agreement with incomplete participation. As in Section 4.1 R\&D expenditures are determined by the signatories in a noncooperative manner. Let $a_{0 i}$ be the amount of abatement in the non-cooperating countries that is purchased by country i. Total acquisition of CDM quotas is then given by 


$$
\sum_{i=1}^{i=N} a_{0 i}=A_{0}
$$

The cost of (cooperating) country $i$ is now given by

$$
x_{i}+C_{i}\left(A_{i}, y_{i}\right)+p\left[N_{i}\left(y_{i}\right)-A_{i}-a_{0 i}-\bar{E}_{i}\right]+q a_{0 i}+D_{i}\left(N_{0}\left(y_{0}\right)+\sum_{j=1}^{j=N} \bar{E}_{j}\right)
$$

Country $i$ takes the prices $p$ and $q$ as given, and wishes to choose $x_{i}, A_{i}$ and $a_{0 i}$ in order to minimize its total costs. If $q<p$ all countries want to purchase only CDM quotas. However, with no demand for tradable quotas, the price of this type of quota drops, and in equilibrium $q=p$. On the other hand, if $A_{0}$ is given and "low", $q<p$ in equilibrium. Note that in order to sustain $q<p$ in equilibrium, the amount $A_{0}$ must be rationed, that is, the agreement must specify for each cooperating country how much abatement it is allowed to purchase in the non-cooperating countries. ${ }^{8}$

For an exogenous $a_{0 i}$, the levels of $x_{i}$ and $A_{i}$ that minimize the expression above are given by (16) and (23). Comparing these equations with the conditions for a first best optimum for the group of cooperating countries, i.e. with (26) and (27), we see that if the sum of quotas is set so that the quota price is equal to the Pigovian level (i.e. $p=\sum_{j} D_{j}^{\prime}$ ), it is clear that equation (27) from the first best optimum of the signatories will be satisfied. However, the technology levels in the cooperating countries will also in the present case be lower than what is optimal, as the reasoning we gave after (16) is valid also in the present case. In fact, in the present case there is even a further distortion, which is due to the last term on the r.h.s. of (26): Individual countries take the price $q$ as given, and therefore neglect the price lowering effect of their R\&D expenditures. The discussion above implies that for the same reason as given in Section 4.1, it is also in the present case optimal to set the sum of emissions so low that the quota price $p$ is higher than the Pigovian level.

\footnotetext{
${ }^{8}$ If $\mathrm{CDM}$ quotas are traded in a competitive market (not purchased by e.g. a monopsonist), $q=p$ in equilibrium.
} 
The main results of this section can be summarized as follows:

Proposition 12: If the cooperating countries can purchase CDM quotas from the noncooperating countries, it is optimal for the group of cooperating countries to act as a monopsonist towards the non-cooperating countries and purchase less abatement than full cost-effectiveness would suggest. Comparing the first best optimum of the group of cooperating countries with the case of an incomplete Kyoto type of agreement with CDM quotas, as in Section 4 the Kyoto type is inferior, having too low technology levels.

\section{Concluding remarks}

We would like to make a few concluding remarks. First, several of our results were proved under rather restrictive assumptions, such as identical countries and/or specific properties of the environmental damage functions. However, by considering the discussions and the proofs, it is clear that these restrictive assumptions are only necessary conditions. The results are thus likely to hold for a much wider class of assumptions, although they are not completely general.

Second, we would like to point out an important policy implication of one of our results. It is sometimes argued that since we can expect lower abatement costs in the future through technological change, current restrictions on greenhouse gas emissions should be moderate. Our analysis has shown that if future technological change is the result of deliberate R\&D effort, this argument may be misleading: Under a Kyoto type of agreement, Proposition 9 suggests that the total amount of quotas should be so strict that the price of emission is higher than what would have been optimal in the absence of endogenous technological change.

Finally, there are a number of possible extensions of the present paper. The most obvious might be the modelling of R\&D: In the paper we have assumed that in each country R\&D expenditures are controlled directly by the government. A more adequate modelling would have been to let the government determine policy instruments, for example, R\&D subsidies, that have impacts on firm's decisions on R\&D expenditures. Within such a framework we could study how policy instruments affect technology spillovers both between firms in the same countries, and between 
firms in different countries. In addition, the rate of technological diffusion $(\gamma)$ could be endogenous and related to firm characteristics, e.g. level of technology. Hence, a topic for future research could be the interplay between policy instruments of different countries, firm incentives to undertake R\&D investments and the rate of technological diffusion. 


\section{References}

Buonanno, B., C. Carraro, E. Castelnuovo, M.Galeotti (2000): Efficiency and equity of emission trading with endogenous environmental technical change. In Carraro C. Efficiency and Equity of Climate Change Policy. Netherlands: Kluwer Academic Publishers, 121-162.

Buonanno, B., C. Carraro, M.Galeotti (2003): Endogenous induced technical change and the costs of Kyoto". Resource and Energy Economics 25, 11-34.

Carraro, C. (1998): "Climate modelling and policy strategies. The role of technological change and uncertainty”, Energy Economics 20, 463-471.

Fischer, C. (2000): "Climate change policy choices and technological innovation", Resources for the Future. Climate Issue Brief 20.

Goulder, L.H. and K. Mathai (2000): "Optimal CO2 abatement in the presence of induced technological change", Journal of Environmental Economics and Management 39, 1-38.

Goulder, L.H. and S. Schneider (1999): „Induced technological change, crowding out, and the attractiveness of $\mathrm{CO} 2$ emissions abatement", Resource and Environmental Economics 21, 211-253.

Hoel, M. (1992a): "Carbon taxes: an international tax or harmonized domestic taxes?", European Economic Review 36, 400-406.

Hoel, M. (1992b): "The Role and Design of a Carbon Tax in an International Climate Agreement", in Climate Change: Designing a Practical Tax System, OECD, Paris.

Hoel, M. (1993): "Harmonization of Carbon Taxes in International Climate Agreements", Environmental and Resource Economics 3, 221-232.

Jaffe, B., G.Newell, R.Stavins (2002): Environmental policy and technological change. Environmental and Resource Economics 22 (special issue), 41-69.

Katsoulacos, Y. (1997): R\&D spillovers, cooperation, subsidies and international agreements. In Carraro C. International Environmental Negotiations. Strategic Policy Issues, 97-109. Cheltenham: Edward Elgar.

Keller, W. (2002): “Geographic Localization of International Technology Diffusion”. American Economic Review 92(1): 120-142.

Kemfert, C. (2001): Economic impact assessment of alternative climate policy strategies. Fondazione Eni Enrico Mattei. Nota Di Lavoro 86.2001.

Löschel, A. (2002): Technological change in economic models of environmental policy: A survey. Ecological Economics, 43, 105-126. 
Millock, K. (2000): Contracts for Clean Development- the role of technology transfers. Fondazione Eni Enrico Mattei. Nota Di Lavoro 70.2000.

Nordhaus, W. D. (2000): "Modeling induced innovation in climate change policy", mimeo, Yale University.

Ploeg, F. and A.Zeeuw (1994): Investment in Clean Technology and Transboundary Pollution control, in Carraro, C., Trade, Innovation, Environment. 229-240. Netherlands, Dordrecht: Kluwer Academic Publishers.

Rasmussen, T. N. (2001): CO2 abatement policy with learning-by-doing in renewable energy. Resource and Energy Economics 23, 297-325.

Rivera-Batiz, L. and P. Romer (1991): "Economic Integration and Endogenous Growth”. Quarterly Journal of Economics, 106: 531-555.

Rosendahl, K., E. (2002): Cost-effective environmental policy: implications of induced technological change. Statistics Norway, Discussion Paper No.314.

Westskog, H. (1996): "Market power in a system of tradable CO" quotas". The Energy Journal 17, 85-103.

Xepapadeas, A. (1995): Induced technical change and international agreements under greenhouse warming. Resource and Energy Economics 17, 1-23. 


\section{APPENDIX: Proof of Propositions 1, 2, 7, 8, 9 and Remark 1.}

\section{Proof of Proposition 1}

Assume the opposite, i.e. that $E^{T} \geq E^{Q}$ (using superscripts $\mathrm{T}$ and $\mathrm{Q}$ to denote the tax and quota equilibrium, respectively, and letting $\mathrm{E}$ denote total emissions). From the convexity of the environmental damage functions this implies $D_{i}^{\prime}\left(E^{T}\right) \geq D_{i}^{\prime}\left(E^{Q}\right)$. Let

$$
\begin{gathered}
C_{i y}^{\prime}\left(A_{i}, y_{i}\right)+N_{i}^{\prime}\left(y_{i}\right) D_{i}^{\prime}(E)=R_{i} \\
C_{i A}^{\prime}\left(A_{i}, y_{i}\right)=S_{i}
\end{gathered}
$$

Since the terms $\left(-\gamma \sum_{k \neq i} N_{k}^{\prime}+\gamma \sum_{k \neq i} A_{k y}^{\prime}\right) D_{i}^{\prime}$ in (13) are positive, the inequality $D_{i}^{\prime}\left(E^{T}\right) \geq D_{i}^{\prime}\left(E^{Q}\right)$ implies from (7), (8) and (13) that $R_{i}^{T}>R_{i}^{Q}$ and $S_{i}^{T} \geq S_{i}^{Q}$ for all i. Differentiating (A1) and (A2) yields:

$$
\begin{gathered}
d y_{i}=\frac{C_{i y A}^{\prime \prime} d N_{i}-C_{i A A}^{\prime \prime} d M_{i}+C_{i A A}^{\prime \prime} N_{i}^{\prime} D_{i}^{\prime \prime} d E}{P_{i}}>0 \\
d A_{i}=\frac{C_{i y A}^{\prime \prime} d M_{i}-C_{i y A}^{\prime \prime} N_{i}^{\prime} D_{i}^{\prime \prime} d E-C_{i y y}^{\prime \prime} d N_{i}-D_{i}^{\prime} N_{i}^{\prime \prime} d N_{i}}{P_{i}}>0
\end{gathered}
$$

where

$$
P_{i}=\left(C_{i A y}^{\prime \prime}\right)^{2}-C_{i A A}^{\prime \prime} C_{i y y}^{\prime \prime}-C_{i A A}^{\prime \prime} D_{i}^{\prime} N_{i}^{\prime \prime}<0
$$

As noted above, a shift from the quota equilibrium to the tax equilibrium implies that $d M_{i}>0, d S_{i} \geq 0, d E_{i} \geq 0$. It therefore follows from (A3), (A4) and (A5) that $d y_{i}>0, d A_{i}>0$, that is, $y_{i}^{T}>y_{i}^{Q}$ and $A_{i}^{T}>A_{i}^{Q}$ for all $\mathrm{i}$, which implies $E^{T}<E^{Q}$. But the latter inequality contradicts our initial assumption. This completes the proof of Proposition 1. 


\section{Proof of Proposition 2}

When $D_{i}\left(\sum_{j} E_{j}\right)=\delta_{i} \sum_{j} E_{j}$, the equilibrium condition (8) may be written as

$$
C_{i A}^{\prime}\left(A_{i}, y_{i}\right)-\delta_{i}=0
$$

while the condition (7) for the quota equilibrium and (13) for the quota equilibrium may be written as

$$
1+C_{i y}^{\prime}\left(A_{i}, y_{i}\right)+N_{i}^{\prime} \delta_{i}=K_{i}
$$

where $K_{i}=0$ in the quota equilibrium and $K_{i}=\gamma\left(-\sum_{k \neq i} N_{k}^{\prime}+\sum_{k \neq i} A_{k y}^{\prime}\right) \delta_{i}>0$ in the tax equilibrium. In both equilibria these two equations for country $i$ determine the abatement level and the technology level in country $\mathrm{i}$ (for a given value of $K_{i}$ ). The difference in the two equilibria can be found by comparing the case of $K_{i}=0$ with the case of $K_{i}>0$. To do this we differentiate (A6) and (A7) with respect to $K_{i}$, which gives

$$
\begin{gathered}
\frac{\partial A_{i}}{\partial K_{i}}=-\frac{C_{i A y}^{\prime \prime}}{H_{i}}>0 \\
\frac{\partial y_{i}}{\partial K_{i}}=-\frac{C_{i A A}^{\prime \prime}}{H_{i}}>0
\end{gathered}
$$

where

$$
H_{i}=C_{i A A}^{\prime \prime} C_{i y y}^{\prime \prime}+\delta_{i} C_{i A A}^{\prime \prime} N_{i}^{\prime \prime}-\left(C_{i A y}^{\prime \prime}\right)^{2}>0
$$

and the signs follow from our assumptions on the abatement cost functions and BAU emission functions. It is thus clear that technology levels and abatement levels are higher in the non-cooperative tax equilibrium than in the non-cooperative quota equilibrium. This completes the proof of Proposition 2. 


\section{Proof of Proposition 7}

Differentiating (15) and (16) with respect to $\mathrm{p}$ gives

$$
\begin{gathered}
\frac{d A_{i}}{d p}=\frac{1}{H_{i}}\left[C_{i y y}^{\prime \prime}+p N_{i}^{\prime \prime}+N_{i}^{\prime} C_{i A y}^{\prime \prime}\right]>0 \\
\frac{d y_{i}}{d p}=\frac{1}{H_{i}}\left[-N_{i}^{\prime} C_{i A A}^{\prime \prime}-C_{i y A}^{\prime \prime}\right]>0
\end{gathered}
$$

where $H_{i}$ is given by (A10) except that $\delta_{i}$ is replaced by $p$. This completes the proof of Proposition 7.

\section{Proof of Proposition 8}

If $p=\sum_{j} D_{j}^{\prime}\left(E_{j}^{S O}\right)$, the social optimum is given by (15) and (16), except that (15) now has an additional positive term $K_{i}=-\gamma\left(\sum_{k \neq i} C_{k y}^{\prime}+p \sum_{k \neq i} N_{k}^{\prime}\right)$. We therefore have exactly the same mathematical structure as in the comparison made in the proof of Proposition 1. It therefore also follows that compared with the social optimum, abatement levels and technology levels will be lower in all countries in the Kyoto type of agreement than in the social optimum. This completes the proof of Proposition 8.

\section{Proof of Proposition 9}

Denote social costs (given by (3)) by $S$. Differentiating the first line of (3) with respect to technology levels gives

$$
d S=\sum_{i} d x_{i}+\sum_{i}\left(C_{i y}^{\prime}+p N_{i}^{\prime}\right) d y_{i}
$$

where we have inserted $p=\sum_{j} D_{j}^{\prime}$. Inserting (15) gives

$$
d S=\sum_{i} d x_{i}-\sum_{i} d y_{i}
$$


From (1) we have

$$
y_{i}=\gamma \sum_{j} x_{j}+(1-\gamma) x_{i}
$$

Taking the sum over all $\mathrm{m}$ countries gives

$$
\sum_{i} y_{i}=\gamma m \sum_{i} x_{i}+(1-\gamma) \sum_{i} x_{i}=[\gamma m+(1-\gamma)] \sum_{i} x_{i}
$$

The term in square brackets is larger than 1. The sum of technology levels is thus proportional to the sum of $R \& D$ expenditures, with a proportionality factor that is larger than one. When $\sum_{i} d y_{i}$ is positive, it therefore must be the case that $\sum_{i} d y_{i}>\sum_{i} d x_{i}$, implying $d S<0$. This completes our proof of Proposition 9.

\section{Proof of Remark 1}

Under both types of agreements we have

$$
C_{A}^{\prime}(A, y)-p=0
$$

Further, condition (15) for the quota equilibrium and condition (18) for the tax equilibrium may be written as

$$
1+C_{y}^{\prime}(A, y)+\eta p=K
$$

with $K=0$ under the quota agreement and $K$ given by (20) under the tax agreement. Note that (A17) and (A18) have the same mathematical structure as (A6) and (A7). From (A8) and (A9) it therefore follows that

$$
\begin{aligned}
& \frac{\partial A}{\partial K}>0 \\
& \frac{\partial y}{\partial K}>0
\end{aligned}
$$

and Remark 1 immediately follows. 